Check for updates

Cite this: Mater. Adv., 2021

2, 1369

Received 16th December 2020

Accepted 15th January 2021

DOI: $10.1039 / \mathrm{d} 0 \mathrm{ma} 00985 \mathrm{~g}$

rsc.li/materials-advances

\title{
Living electrodes based on green algae in hydrogels
}

\author{
Mohammed Al-Mossawi, ${ }^{a}$ Holly Warren, (D) b Paul J. Molino, (D) ${ }^{b}$ Paul Calvert ${ }^{c}$ and \\ Marc in het Panhuis (iD *a
}

\begin{abstract}
Soft and living electrodes offer new possibilities for addressing the biological-electrical interface beyond the use of traditional metal based bio-electrodes. Here, we present a living electrode material from green algae "Chlorella vulgaris" embedded within alginate hydrogel and cross-linked at different calcium chloride concentrations. Mechanical, rheological, electrical and biological properties of the living electrode materials were assessed to investigate the impact of algal growth on the characteristics of resulting gels. The electrical behaviour of the algae/alginate hydrogels was characterised using electrical impedance spectroscopy. Living electrodes containing algae exhibit conductivity values of up to $4.9 \pm$ $0.2 \mathrm{~ms} \mathrm{~cm}^{-1}$. These conductivity values were sufficient to use these living hydrogels as electrode components in simple electrical circuits.
\end{abstract}

\section{Introduction}

Electrode technology is key in a variety of fields ${ }^{1}$ including chemical analysis, ${ }^{2}$ fuel cells, ${ }^{3}$ photovoltaics, ${ }^{4}$ catalysis ${ }^{5}$ (i.e. water splitting) and biomedical applications to name but a few. ${ }^{6}$ Technological advancements of electrodes have allowed tremendous new opportunities within the area of bioelectronics. ${ }^{7}$ Traditionally, bio-electronic interfaces have been constructed through the use of inert conductive materials, such as gold and platinum, ${ }^{8}$ however, due to the material physicochemical and mechanical properties (i.e. high stiffness/modulus), they generally interface poorly with biological cells and tissues. ${ }^{9}$ As such, research has been focused on developing more mechanically and chemically compliant materials for use in bioelectronics applications. For example, living cells enclosed in a hydrogel substrate have been used to replace and enhance traditional conductive substrates (such as a metal probe or wire $)^{7}$ for biological applications owing to their improved mechanical properties, and enhanced bio interfacing through tailoring of hydrogel chemistry. ${ }^{10}$ Biological cells and organisms, including mammalian cells, bacteria and algae, are allowed to grow in the electrically conductive hydrogel. The electrically conductive substrate can then make contact with (or be inserted into) living tissue or a biological environment to generate a biological interfaced electrode, or a 'living electrode'. ${ }^{11}$

\footnotetext{
${ }^{a}$ School of Chemistry and Molecular Bioscience, University of Wollongong, Wollongong, NSW 2522, Australia. E-mail: panhuis@uow.edu.au

${ }^{b}$ ARC Centre of Excellence for Electromaterials Science, University of Wollongong, Wollongong, NSW 2522, Australia

${ }^{c}$ University of New Mexico Tech, Soccorro, NM, USA
}

Fundamentally, living electrodes are used to improve the interface between inorganic and organic surfaces. ${ }^{12}$ Recently, living electrodes have been the subject of several studies, where hydrogel electrodes have been developed incorporating enzymes, bacteria $^{6}$ and blue-green algae. ${ }^{13}$ The development of a living electrode using blue-green algae was performed by immobilizing the algae on $\mathrm{SnO}_{2}$, an optically transparent electrode, with calcium alginate. The electrode demonstrated a unique ability to convert solar energy into electrical energy, producing a distinctive type of electrochemical cell. ${ }^{14}$ The use of such electrodes has been shown to provide efficient conversion of solar radiant energy to electric energy using the blue-green algae Mastigocladus laminosus. ${ }^{15}$ Other work has shown much progress in the application of eukaryotic cells to produce a living electrode. It has been demonstrated that layered conductive hydrogel $(\mathrm{CH})$ constructs, embedded with neural cells, ${ }^{16}$ support cell growth and maintenance of electro activity. ${ }^{15}$

Living electrode systems have the potential to be applied over a range of disciplines, from energy harvesting to neural interfaces. However, many living electrode systems currently in development for biomedical applications are hampered by their use of metals such as platinum and gold that interface poorly in biological systems, or by the high sensitivity of the cells type (i.e. mammalian) employed on the metallic electrode or in the hydrogel electrode, limiting potential applications. ${ }^{17,18}$ To overcome these issues, more robust cell types ${ }^{7}$ and/or unicellular organisms $^{19}$ need to be investigated, of which microalgae are a particularly attractive candidate.

Microalgae are part of an ancient group, comprising some of the oldest known biological organisms (dating back 3.4 billion years), and are ubiquitous in almost every ecosystem on earth. ${ }^{20}$ 
Many microalgae are unicellular in nature and possess an ability to produce chemical energy from solar energy via photosynthesis. $^{21}$ Recently, microalgae have become an important component in the formation of dyes, aquaculture, animal feed and cosmetics. ${ }^{22}$

The archetypical unicellular green algae, Chlorella, ${ }^{23}$ are pervasive in aquatic and terrestrial ecosystems. ${ }^{24,25}$ The algae perfectly typify experimental model organisms, which show biochemical and physiological properties of micro and macrophytes. ${ }^{26}$ The survival of green algae species in liquid media exhibit several hindrances to growth, such as potential toxicity of reactants and products, and nutritional limitations. ${ }^{27,28}$ Immobilisation of microalgal cells within hydrogel materials has shown promising outcomes for the maintenance and growth of cells, with the hydrogel acting to protect the cells from contaminants, dehydration and the other harsh condition that may lead to cell death. ${ }^{25}$ Several studies have successfully demonstrated the immobilisation of microalgae and mammalian cells into different hydrogel materials or hydrogel scaffolds. ${ }^{29}$ Some of these hydrogel materials have been specifically tailored to mimic a specific microenvironment, such as various tissue types (i.e. nerve, muscle, bone). ${ }^{30}$

Encapsulation of living cells in an inert, biologically compatible matrix can provide several advantages, in particular the protection of cells from environmental stresses, including dehydration and exposure to toxic compounds. ${ }^{31}$ Hydrogels are ideal materials for immobilisation of algae due to their unique materials properties including high water content, ability for gas and nutrient exchange as well as mechanical characteristics that can be readily tailored. ${ }^{32}$ Hydrogels are a three-dimensional network of hydrophilic polymers that absorb and retain water in amounts that greatly exceed their dry weight. ${ }^{33}$ Network formation and insolubility in aqueous media are due to the presence of chemical cross-linking or physical entanglement. ${ }^{34}$ Moreover, hydrogels are an important class of biomaterials that are widely used in the pharmaceutical and biomedical sectors, ${ }^{35}$ particularly those that are derived from naturally occurring biopolymers. Among the naturally occurring biopolymers, alginate and gelatine are extensively used for many biomedical applications because of their biocompatibility and biodegradability. ${ }^{36}$

Alginate's popularity as a commercial and scientific material is a result of its biocompatibility, low toxicity, low cost, ease of gelation induced by divalent cations (i.e. $\mathrm{Ca}^{2+}$ ) and facile immobilization of macromolecules and cells. ${ }^{37}$ Furthermore, alginate gels may be taken orally or injected into the body, making them an important component in the pharmaceutical industry. ${ }^{35}$ They have shown promising results in cell transplantation and tissue engineering, ${ }^{38-40}$ and are widely employed as a model system for mammalian cell culture in biomedical studies. ${ }^{29}$

In this paper, we focus on immobilising $C$. vulgaris cells into an alginate network to produce an algae/alginate based living electrode. Ionic hydrogel crosslinking with $\mathrm{CaCl}_{2}$, and addition of hydroxyapatite (HAP) were used to enhance the strength of the alginate network. The living electrodes were characterized by investigating the effect of algal growth on mechanical, electrical impedance, rheological and biological characteristics of the hydrogel network. We show that our living hydrogel can function as electrodes in simple circuits.

\section{Experimental}

\section{Materials and methods}

Green algae-Chlorella was obtained from Southern Biological, NSW, Australia. Chlorella culture medium CM3 (obtained from Southern Biological, NSW, Australia). $\mathrm{CaCl}_{2} \cdot 2 \mathrm{H}_{2} \mathrm{O}$ (Sigma Aldrich, Australia, lot number: MKBG9652V). Sodium alginate and sodium bicarbonate (Sigma, UK). Green and red LEDs, standard electrical cables and DC power source were purchased from Jaycar (Shellharbour, NSW, Australia).

$10 \mathrm{~mL}$ of Chlorella stock solution was added to $30 \mathrm{~mL}$ of Chlorella culture medium CM3 (ratio 1:3) into a sterile $500 \mathrm{ml}$ conical flask. Then, $50 \mathrm{~mL}$ of sterilised Milli-Q water Milli-Q water (resistivity, $18.2 \mathrm{M} \Omega \mathrm{cm}$ ) and 10 drops of $2 \%$ sodium bicarbonate was added to the solution. The algal cells were cultivated under light simulated illumination at $20 \mu \mathrm{mol} \mathrm{m} \mathrm{m}^{-2} \mathrm{~s}^{-1}$ with a light to dark photoperiod of 10-14 h. Light stimulation was performed on a flask shaker (Bioline orbital shaker BL8136, Australia). The algae were cultured for 28 days at $21{ }^{\circ} \mathrm{C}$.

\section{Preparation of hydrogels}

Three types of algae/alginate gels were constructed by dissolving $4 \%$ sodium alginate $(\mathrm{w} / \mathrm{w})$ in $100 \mathrm{~mL}$ Milli-Q water under rapid stirring (1000 rpm) and heated to $60{ }^{\circ} \mathrm{C}$ for 2 hours until a homogenous solution was obtained. Type 1 algae/alginate gels (E1) was prepared by using $0.05 \mathrm{M} \mathrm{CaCl}_{2}$ as ionic crosslinker, while an increased crosslinker concentration of $0.1 \mathrm{M}$ was used to prepare type 2 gel (E2). Type 3 gels (E3) was prepared by adding $2 \%(\mathrm{w} / \mathrm{w})$ of hydroxyapatite (HAP) to the $\mathrm{E} 2 \mathrm{gel}$.

\section{Hydrogel encapsulation of algae}

Algae/alginate gels were constructed by mixing $3 \mathrm{~mL}$ of preprepared cultivated algal cells (approximately $3 \times 10^{5}$ cells per $\mathrm{mL}$ ) with $5 \mathrm{~g}$ with sodium alginate solutions. The solutions were poured into different sized moulds depending on the particular test requirement. Thereafter, E1 samples were immersed in a crosslinking bath of $0.05 \mathrm{M} \mathrm{CaCl}_{2}$, while E2 and E3 were crosslinked with $0.1 \mathrm{M} \mathrm{CaCl}_{2}$. All samples were left for 3 hours under controlled conditions $\left(21{ }^{\circ} \mathrm{C}\right.$ and $45 \%$ relative humidity). Since the ionic crosslinking reaction is instantaneous, living algal cells were quickly entrapped inside the alginate hydrogel network. The gel samples (diameter $15 \mathrm{~mm}$ ) were rinsed with Mill-Q water to ensure all excess calcium ions were removed from the gel. The algae/alginate gels were placed into sterile $120 \mathrm{~mL}$ sterile plastic containers filled with $50 \mathrm{~mL}$ of Milli-Q water and $10 \mathrm{~mL}$ of culture medium (CM3). They were then cultured under light illuminated culture conditions on the orbital stirrer.

\section{Determination of oxygen release}

Algae/alginate gels were transferred to a $100 \mathrm{~mL}$ sterile bottle containing $50 \mathrm{~mL}$ Milli-Q water. The bottle was closed by a 
screwcap to avoid oxygen or other gas exchange with the surrounding air. Values of oxygen release from the algae/ alginate gels into the media was detected by measuring the change of oxygen concentration using a dissolved oxygen meter (HORIBA - OM-71, Japan). Measurements were taken (in triplicate) every $1,7,14,21$ and 28 days of cultivation period.

\section{Microscopy}

Algae/alginate gels were incubated in CM3 culture medium under controlled conditions and illumination. At different cultivation periods, the growth of the algae embedded within the hydrogels and their viability evaluated using fluorescence imaging and staining. Cell numbers and biomass were qualitatively studied by imaging chloroplast auto fluorescence at several regions within the hydrogel using a Leica (TSC SP5 II) Scanning Laser Confocal Microscope (SLCM). Fluorescein diacetate (FDA) was also used to determine the viability of cells both in liquid media and embedded within the hydrogel networks. For FDA staining, plastic test tubes were filled with $3 \mathrm{~mL}$ of algal cell suspension that were prepared as described above. Suspensions were centrifuged at $6000 \mathrm{rpm}$ for $5 \mathrm{~min}$ to collect the cells and establish a concentrated solution of $3 \times$ 105 cells per $\mathrm{mL}$ at the first time zero. PBS was used twice to wash the cells and replace the supernatant liquid. The cells were added to the alginate gel for making algae/alginate gels then treated with $2 \%$ FDA. These samples were kept in dark for $10 \mathrm{~min}$ at room temperature $\left(21^{\circ} \mathrm{C}\right)$. Three replicates were prepared and carried out to measure cell concentration and viability over time.

\section{Biomass measurement}

Hydrogel dry mass and algal dry biomass was calculated in the gels at regular intervals $(1,3,7,14,21$ and 28 days) by removing the solvent in an oven at $60{ }^{\circ} \mathrm{C}$. The dry weight of algal cells was calculated using the total suspended solids method to quantify algal growth. The dry mass (DM) was calculated to obtain the dry cell weight of algae using:

$$
\mathrm{DM}=\frac{\mathrm{DW}_{\mathrm{AG} / \mathrm{Alg}}-\mathrm{DW}_{\mathrm{AG}}}{V_{\mathrm{d}}},
$$

where $V_{\mathrm{d}}$ is a volume used $(\mathrm{ml})$ and $\mathrm{DW}_{\mathrm{AG} / \mathrm{Alg}}$ and $\mathrm{DW}_{\mathrm{AG}}$ are weight of dried gel with and without algae, respectively.

\section{Swelling ratio}

The swelling ratio $(Q)$ of the gels with and without algae was determined after soaking the gels in Milli-Q water using:

$$
Q=\frac{W_{\mathrm{s}}-W_{\mathrm{d}}}{W_{\mathrm{d}}} \times 100 \%,
$$

where $W_{\mathrm{s}}$ and $W_{\mathrm{d}}$ are the swollen mass and the dried mass of the hydrogel, respectively.

\section{Mechanical analysis}

Compression testing was performed using a universal mechanical test (EZ-S, Shimadzu, Japan, cross-head speed $=1 \mathrm{~mm} \mathrm{~min}^{-1}$, $50 \mathrm{~N}$ load cell at $21{ }^{\circ} \mathrm{C}$ and $45 \%$ relative humidity). Trapezium $\mathrm{X}$ software was used to record the data. Stress-strain curves were used to calculate the compressive stress at failure $\left(\sigma_{c}\right)$, compressive modulus (strain range $20-30 \%, E_{\mathrm{c}}$ ), and compressive strain at failure $\left(\varepsilon_{\mathrm{c}}\right)$.

\section{Rheology}

Rheological analysis was performed using an Anton Paar Physica MCR 301 digital Rheometer (Parallel plate; $15 \mathrm{~mm}$ diameter). Cylindrical samples were prepared with $15 \mathrm{~mm}$ diameter and $3 \mathrm{~mm}$ height. Strain-sweep experiments were carried out across a strain range of $10^{-2}-10^{2}$ at a fixed frequency of $10 \mathrm{~Hz}$ and $21{ }^{\circ} \mathrm{C}$. Storage modulus $\left(G^{\prime}\right)$ and loss modulus $\left(G^{\prime \prime}\right)$ were determined for all samples within the linear viscoelastic region (LVE).

\section{Electrical Impedance and circuit}

Impedance measurement was carried out using a GAMRY reference 600 ZRA Machine. The impedance measurements were conducted on gels with cross-sectional area (Ac) of $5 \mathrm{~cm} \times$ $0.3 \mathrm{~cm}$ and different lengths $(l)$ (range of $0.5-2.5 \mathrm{~cm}$ ). Impedance analysis was performed by applying $10 \mathrm{mV}$ (alternating current) and a frequency between $0.1 \mathrm{~Hz}-1 \mathrm{MHz}$ with an estimated reference resistance which was chosen by applying a voltage from a multimeter through the gel prior to measurements. The conductivity $(\sigma)$ of the gels can be determined by plotting the resistance in the frequency independent region $\left(R_{\mathrm{I}}\right)$ versus $l$ using the following equation:

$$
R_{\mathrm{I}}=\frac{l}{\sigma A c}+R_{\mathrm{c}}
$$

where $R_{\mathrm{c}}$ is contact resistance. Equivalent circuit modelling was used to determine the impedance behaviour of the gels, using a three-parameter fit of a resistor in series with a Warburg element and a capacitor.

Simple circuits were prepared by connecting green/red LEDs with algae/alginate electrodes in series to a DC power source. The required DC current and voltage was applied to power the LEDs.

\section{Results and discussion}

Hydrogels with algae were prepared by immobilizing the Chlorella cells in alginate hydrogel (Fig. 1a). Gels E1 and E2 are composed of algae/alginate gels crosslinked with $0.05 \mathrm{M} \mathrm{CaCl}_{2}$ and $0.10 \mathrm{M}$ $\mathrm{CaCl}_{2}$, respectively, and gel E3 involved addition of $2 \%(\mathrm{w} / \mathrm{w})$ of hydroxyapatite and crosslinked with $0.10 \mathrm{M} \mathrm{CaCl}_{2}$.

\section{Growth and viability of algae}

Oxygen is a by-product of the photosynthesis process undertaken by the algal cells, and as such is an excellent method to monitor the viability and population growth of algal cells within our hydrogel network. Fig. 2a shows the concentration of oxygen produced over 28 days by the algae within Hydrogels E1-E3.

The results show a steady increase in the total oxygen produced by the algae within the scaffolds over time, indicating 

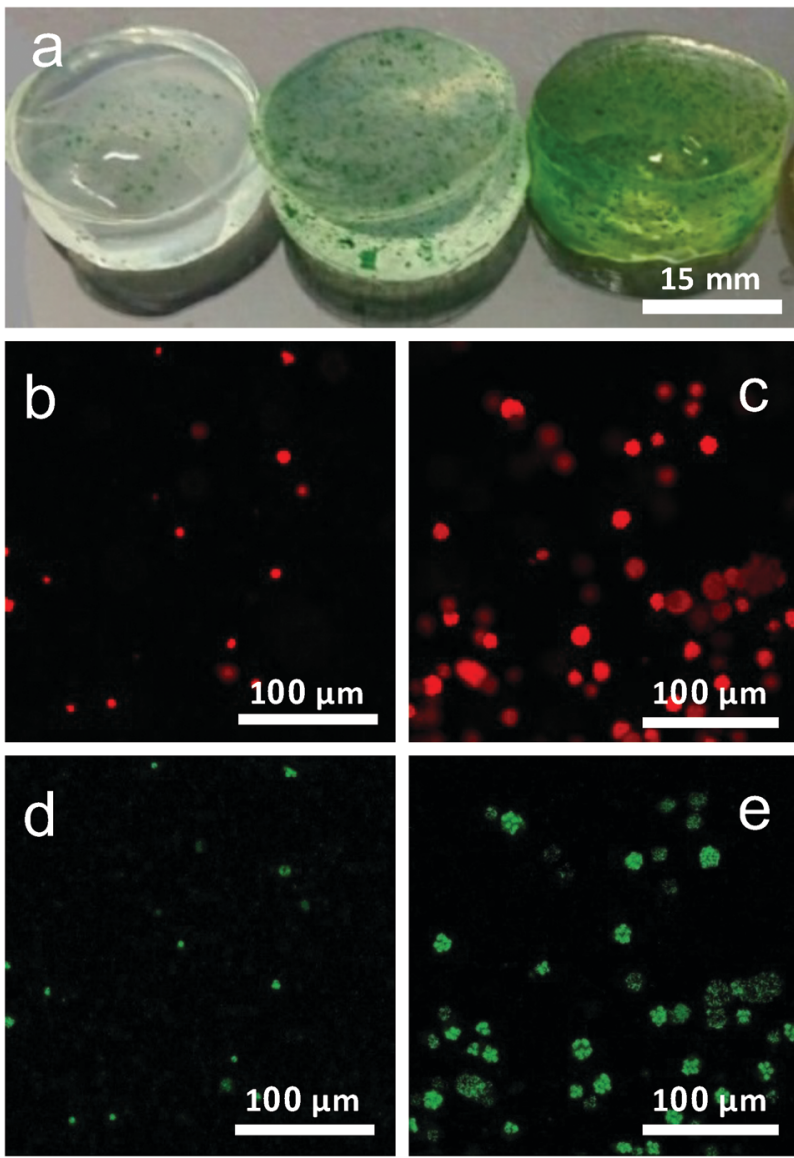

Fig. 1 (a) Photograph showing the growth of algae cells within the alginate network over time (from left to right) at 1, 7 and 14 days of cultivation. (b-e) Confocal pictures show the growth of algae cells within alginate networks over time. (b) and (c) growth of algae after 1 and 14 days of cultivation using the fluorescence of the cell chloroplasts, respectively. (c) and (d) growth of algae after 1 and 14 days of cultivation using the fluorescein diacetate stain, respectively.

good viability of cells within the scaffolds, as well as the steady increase in cell numbers during the cultivation period.

At day 1, the dissolved oxygen amount present in all algae/ alginate gels was roughly equivalent to each other (Fig. 2). The dissolved oxygen for all gels increased over the next 28 days, providing a clear indication that the algae were able to proliferate, indicated that alginate is a suitable hydrogel scaffold to support the growth of the algae. From day 3 onwards, the highest amount of dissolved oxygen amount was observed for Hydrogel E1 followed by $\mathrm{E} 2$ and then E3. After 28 days the amount of dissolved oxygen present in the gels were as follows, with $11.6 \pm 0.4 \mathrm{mg} \mathrm{L}^{-1}$ (Hydrogel E1), $10.8 \pm 0.2 \mathrm{mg} \mathrm{L}^{-1}$ (Hydrogel E2) and $9.6 \pm$ $0.1 \mathrm{mg} \mathrm{L}^{-1}$ (Hydrogel E3).

Confocal imaging was used to investigate and track the growth of algal cells within the gel over the period of cultivation. Fig. $1 \mathrm{~b}$ and $\mathrm{c}$ shows demonstrates the employment of autofluorescence imaging of the cell chloroplasts to identify active cells within the gel and follow their mode of growth in the gel over time. Imaging of chloroplast autofluorescence clearly revealed cells to grow in 'clusters' overtime, confined to pockets within
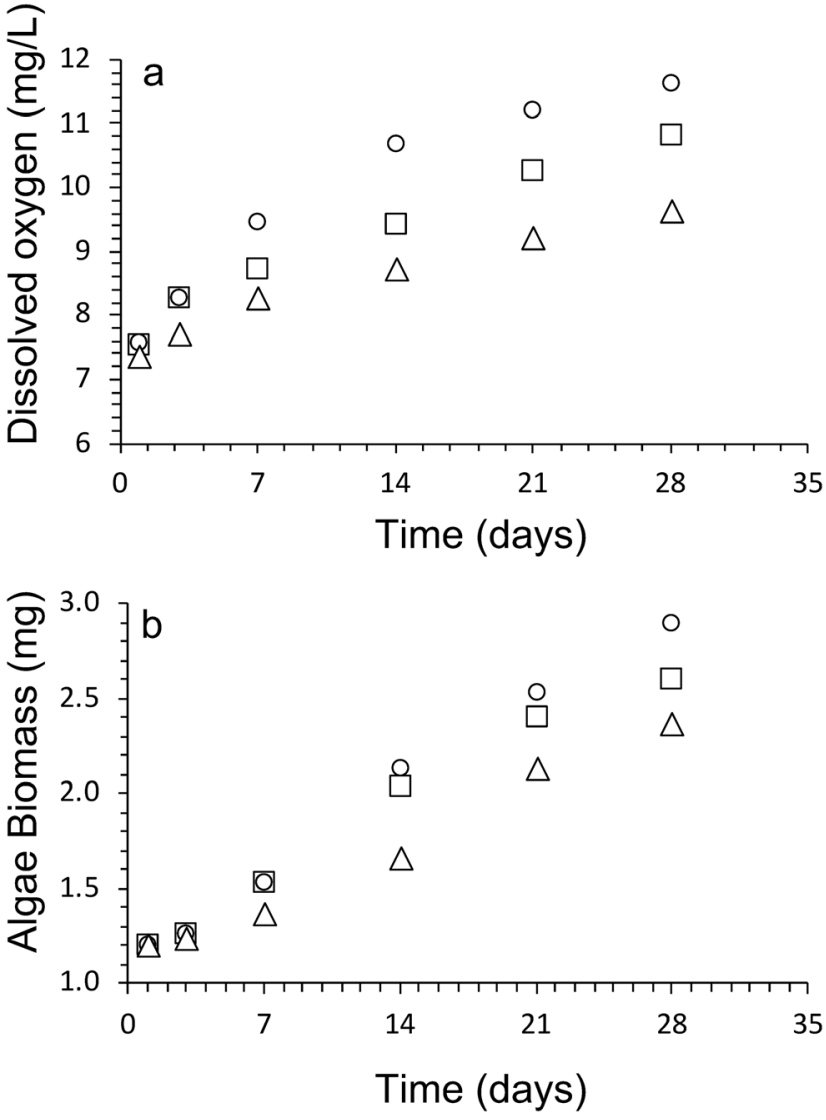

Fig. 2 (a) Dissolved oxygen concentration as a function of cultivation time from three types of algae/alginate gels (E1, spheres) with $0.05 \mathrm{M}$ $\mathrm{CaCl}_{2}$, (E2, squares) $0.10 \mathrm{M} \mathrm{CaCl}_{2}$, (E3, triangles) $0.10 \mathrm{M} \mathrm{CaCl}_{2}$ with hydroxyapatite. (b) Biomass of algae cells as a function of cultivation time from three types of algae/alginate gels (E1, spheres) with $0.05 \mathrm{M} \mathrm{CaCl}_{2}$, $(\mathrm{E} 2$, squares) $0.10 \mathrm{M} \mathrm{CaCl}_{2}$, (E3, triangles) $0.10 \mathrm{M} \mathrm{CaCl}_{2}$ with hydroxyapatite.

the gel rather than migrate throughout the gel after cell division (Fig. 1b and c).

In addition to this, fluorescein diacetate (FDA) indicator was used to assess the viability of the cells. ${ }^{4}$ This staining technique provides reliable results of cell viability, using the activity of esterase within the cell to convert the non-fluorescent dye FDA into the fluorescent fluorescein, which can be fluorescently imaged (Fig. 1d and e.). Cells showed excellent viability both in the early stages of the experiment, and after several weeks within the gel, indicating the gels to provide a good microenvironment for the proper maintenance of active Chlorella sp. cells.

A dry cell weight method (eqn (1)) was used to measure the biomass of algal cells within the alginate networks (Fig. 2b). The amount of algae biomass increases with cultivation time. For example, the biomass of Hydrogel E1 increases from $1.2 \pm$ $0.4 \mathrm{mg}$ after 1 day to $2.9 \pm 0.6 \mathrm{mg}$ after 28 days of cultivation. Hydrogel E3 produced the smallest amount of biomass $(2.4 \pm$ $0.6 \mathrm{mg}$ ) after 28 days of cultivation. In addition, we observed that the amount of dissolved oxygen produced increases linearly with amount of biomass produced (Fig. 3). A fit of the data of all three hydrogels returned a rate of $2.0 \pm 0.3 \mathrm{mg} \mathrm{L}^{-1}$ of dissolved oxygen per $\mathrm{mg}$ of algae biomass over 28 days of cultivation. 


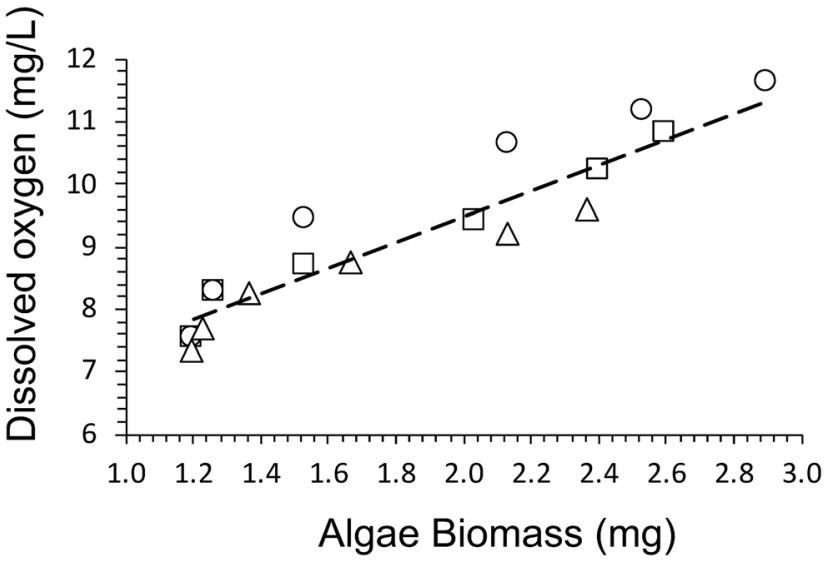

Fig. 3 Dissolved oxygen concentration as a function of algae biomass over 28 days of cultivation for algae/alginate gels (E1, spheres) crosslinked with $0.05 \mathrm{M} \mathrm{CaCl}_{2}$, (E2, squares) $0.10 \mathrm{M} \mathrm{CaCl}_{2}$, and (E3, triangles) $0.10 \mathrm{M}$ $\mathrm{CaCl}_{2}$ with hydroxyapatite. Dashed line is a linear fit to the data.

\section{Swelling behaviour}

The swelling characteristics of gels were calculated with eqn (2) and used to assess physical and mechanical properties of the three gel compositions over time. First, the swelling ratio of gels prepared without algae was evaluated over 28 days (Fig. 4a).
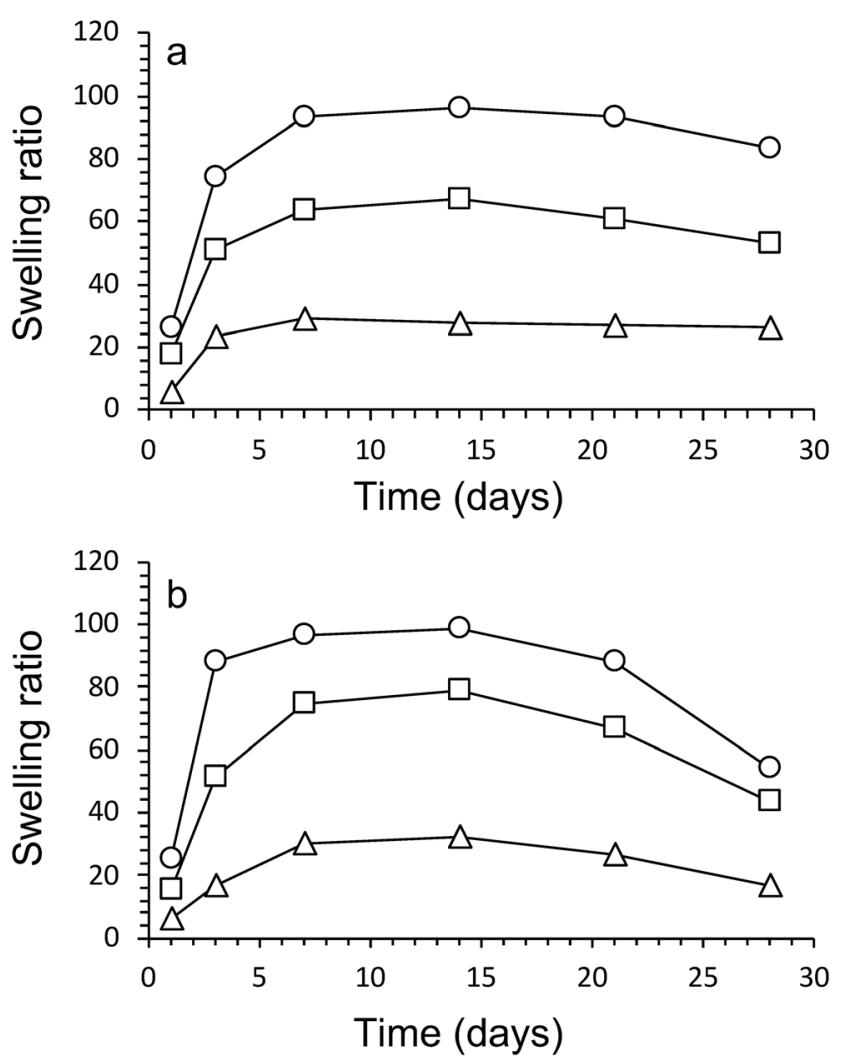

Fig. 4 Swelling ratios as a function of cultivation time. (a) alginate gels (spheres) crosslinked with $0.05 \mathrm{M} \mathrm{CaCl}_{2}$, (squares) $0.10 \mathrm{M} \mathrm{CaCl}_{2}$, and (triangles) $0.10 \mathrm{M} \mathrm{CaCl}_{2}$ with hydroxyapatite. (b) algae/alginate gels (E1, spheres) crosslinked with $0.05 \mathrm{M} \mathrm{CaCl}_{2}$, (E2, squares) $0.10 \mathrm{M} \mathrm{CaCl}_{2}$, and (E3, triangles) $0.10 \mathrm{M} \mathrm{CaCl}_{2}$ with hydroxyapatite.
The swelling behaviour over time was similar for all three gels. A rapid increase in swelling between cultivation days 1 and 3, followed by a slower increase after day 3 until maximum swelling is reached at cultivation day 14 . The maximum swelling values were different with Hydrogels E3 (without algea) showing swelling the least $(Q=28 \pm 2)$ and Hydrogels E1 (without algae) swelling the most $(Q=96 \pm 1)$. The swelling exhibited for Hydrogel E2 (without algae) was in between with $Q=67 \pm 1$. Subsequently, over the next 2 weeks the swelling amount decreases due to a combination of diffusion and evaporation. The values are consistent with the difference in $\mathrm{CaCl}_{2}$ crosslinker (0.05 $\mathrm{M}$ for E1, but $0.10 \mathrm{M}$ for E2 and E3) and addition of hydroxyapatite (only for E3).

The effect of the inclusion of algae in gels can be evaluated from the data presented in Fig. 4b. There is little to no effect in the swelling amounts as a result of incorporation of algae up until cultivation day 14 . However, over the next 2 weeks the swelling amount decreases faster for gels with algae than without. For example, the swelling amount for Hydrogel E2 without algae decreased from $Q=67 \pm 1$ (day 14) via $Q=61 \pm 1$ (day 21) to $Q=53 \pm 2$ (day 28). In contrast, the corresponding values for E2 with algae are $Q=79 \pm 5$ (day 14) via $Q=67 \pm 1$ (day 21) to $Q=43 \pm 1$ (day 28). It is suggested that the higher
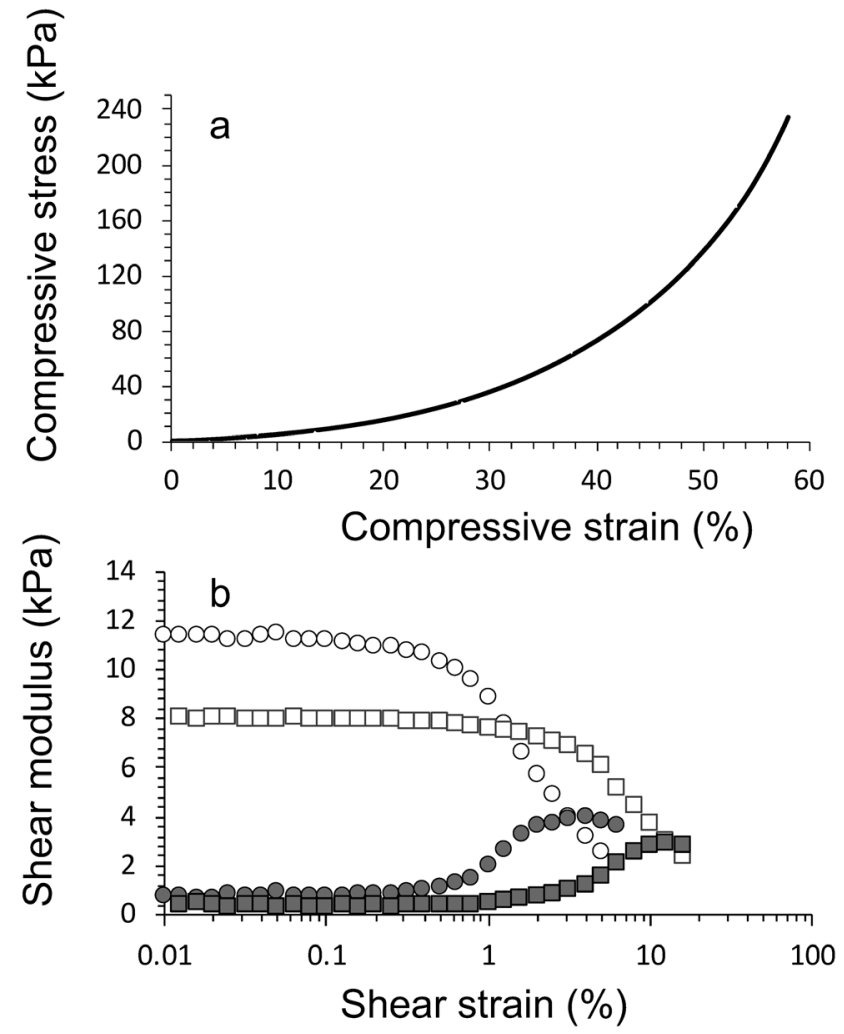

Fig. 5 (a) Compressive stress as a function of compressive strain for algae/alginate gels crosslinked with $0.05 \mathrm{M} \mathrm{CaCl}_{2}$ after 1 day of cultivation. (b) Shear modulus values of alginate gels crosslinked with $0.10 \mathrm{M} \mathrm{CaCl}_{2}$ (storage and loss modulus indicate by open and filled spheres, respectively) and algae/alginate gels crosslinked with $0.10 \mathrm{M} \mathrm{CaCl}_{2}$ (storage and loss modulus indicate by open and filled squares, respectively) after 1 day of cultivation. 
Table 1 Summary of mechanical characteristics from compression testing of algae-alginate gels E1 (crosslinked with $0.05 \mathrm{M} \mathrm{CaCl}$ ), E2 (crosslinked $\left.0.10 \mathrm{M} \mathrm{CaCl}_{2}\right)$ and E3 (2\% hydroxyapatite and crosslinked $\left.0.10 \mathrm{M} \mathrm{CaCl}_{2}\right)$ at $21^{\circ} \mathrm{C}$. Time, $\varepsilon_{\mathrm{c}}$ and $\sigma_{\mathrm{c}}$ indicate cultivation time, compressive modulus (at $20-$ $30 \%$ strain) and compressive stress at failure, respectively

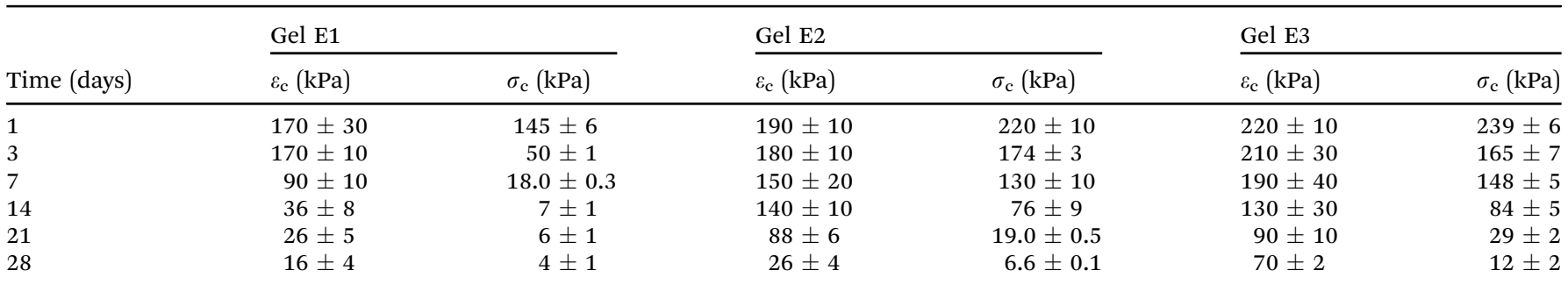

amount of swelling observed for gels containing algae could be a result of the algae consuming the ionic crosslinking agent $\left(\mathrm{Ca}^{2+}\right)$ as a nutrient. It is also likely that the increase in algae biomass can disrupt the crosslinking between polymers. Both of these process results in weaker gels, which leads to the well-known effect of increased swelling. The mechanical data presented below appear to be in support of weaker gels due to the presence of algae.

\section{Mechanical characterisation}

Compression testing and rheology was used to investigate the mechanical characteristic of algae/alginate gels as a function of algal growth (Fig. 5 and Tables 1, 2). Hydrogels were tested 1, 3, 7, 14, 21 and 28 days after preparation, with and without cultivating algal cells. It was illustrated that the magnitude of the mechanical properties significantly decreased over time of for all hydrogels.

As expected, the compressive modulus and compressive strain values increased in crosslinking concentration and addition of HAP (Table 1). Increasing the $\mathrm{CaCl}_{2}$ crosslinker concentration from $0.050 \mathrm{M}$ to $0.10 \mathrm{M}$ resulted in an increase in compressive modulus from $170 \pm 30 \mathrm{kPa}$ (E1 gel, day 1) to $190 \pm 10 \mathrm{kPa}$ (E2 gel, day 1). Addition of HAP (with no change to $\mathrm{CaCl}_{2}$ concentration) further increased the magnitude of the modulus to $220 \pm 10 \mathrm{kPa}$ (E3 gel, day 1$)$.

Overall, all hydrogels displayed the same trend, i.e. decreasing compressive stress and modulus value over the duration of the cultivation period. After 28 days there was little difference between samples. It is suggested that this is a result of the well-known effect of swelling of the hydrogel networks. During swelling water

Table 2 Summary of selected mechanical characteristics from rheological testing of alginate gels $\mathrm{A} 2$ (crosslinked $0.10 \mathrm{M} \mathrm{CaCl}_{2}$ ) and $\mathrm{A} 3(2 \%$ hydroxyapatite and crosslinked $0.10 \mathrm{M} \mathrm{CaCl}_{2}$ ), and algae-alginate gels E2 (crosslinked $0.10 \mathrm{M} \mathrm{CaCl}_{2}$ ) and $\mathrm{E} 3$ (2\% hydroxyapatite and crosslinked $0.10 \mathrm{M}$ $\mathrm{CaCl}_{2}$ ) at $21^{\circ} \mathrm{C}$. Time indicates cultivation time

\begin{tabular}{|c|c|c|c|c|}
\hline Time (days) & Gel A2 (no algae) & Gel E2 & Gel A3 (no algae) & Gel E3 \\
\hline 1 & $10.1 \pm 0.2$ & $8.1 \pm 0.1$ & $16.1 \pm 0.4$ & $12.8 \pm 0.2$ \\
\hline 3 & $4.2 \pm 0.1$ & $3.6 \pm 0.2$ & $5.5 \pm 0.1$ & $3.8 \pm 0.1$ \\
\hline 7 & $3.9 \pm 0.1$ & $3.0 \pm 0.1$ & $5.0 \pm 0.1$ & $3.7 \pm 0.1$ \\
\hline 14 & $3.6 \pm 0.2$ & $2.6 \pm 0.1$ & $4.4 \pm 0.1$ & $2.6 \pm 0.1$ \\
\hline 21 & $1.8 \pm 0.1$ & $1.0 \pm 0.1$ & $1.9 \pm 0.1$ & $1.0 \pm 0.1$ \\
\hline 28 & $1.1 \pm 0.1$ & $0.8 \pm 0.2$ & $1.4 \pm 0.1$ & $0.9 \pm 0.1$ \\
\hline
\end{tabular}

is incorporated which softens and weakens the hydrogel network. There is an additional effect with the algae consuming $\mathrm{Ca}^{2+}$, leading to a reduction in the ionic cross-linking and hence the mechanical characteristics, which is further explored below.

The compression testing results are supported by the findings from rheology, i.e. storage modulus values increased increase in crosslinking concentration and addition of HAP (Table 2). The inclusion of algae within the networks lowers the storage modulus of the materials (Fig. 6a). For example, the storage modulus of algae/alginate ( $2 \%$ hydroxyapatite and crosslinked
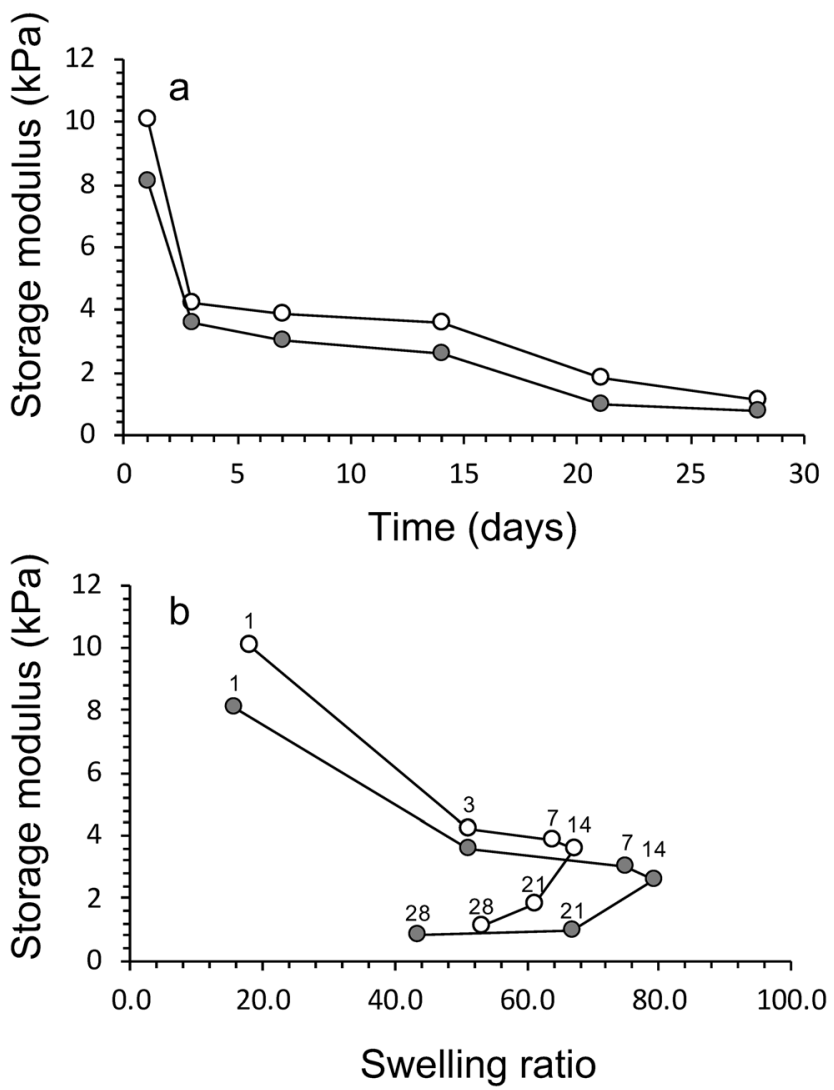

Fig. 6 (a) Storage modulus values of alginate gels crosslinked with $0.05 \mathrm{M}$ $\mathrm{CaCl}_{2}$ (open spheres) and algae/alginate gels crosslinked with $0.05 \mathrm{M}$ $\mathrm{CaCl}_{2}$ (filled spheres) as a function of cultivation time. (b) Storage modulus values of alginate gels crosslinked with $0.05 \mathrm{M} \mathrm{CaCl}_{2}$ (open spheres) and algae/alginate gels crosslinked with $0.05 \mathrm{M} \mathrm{CaCl}_{2}$ (filled spheres) as a function of swelling ratio. Numbers indicate the days of cultivation time. 

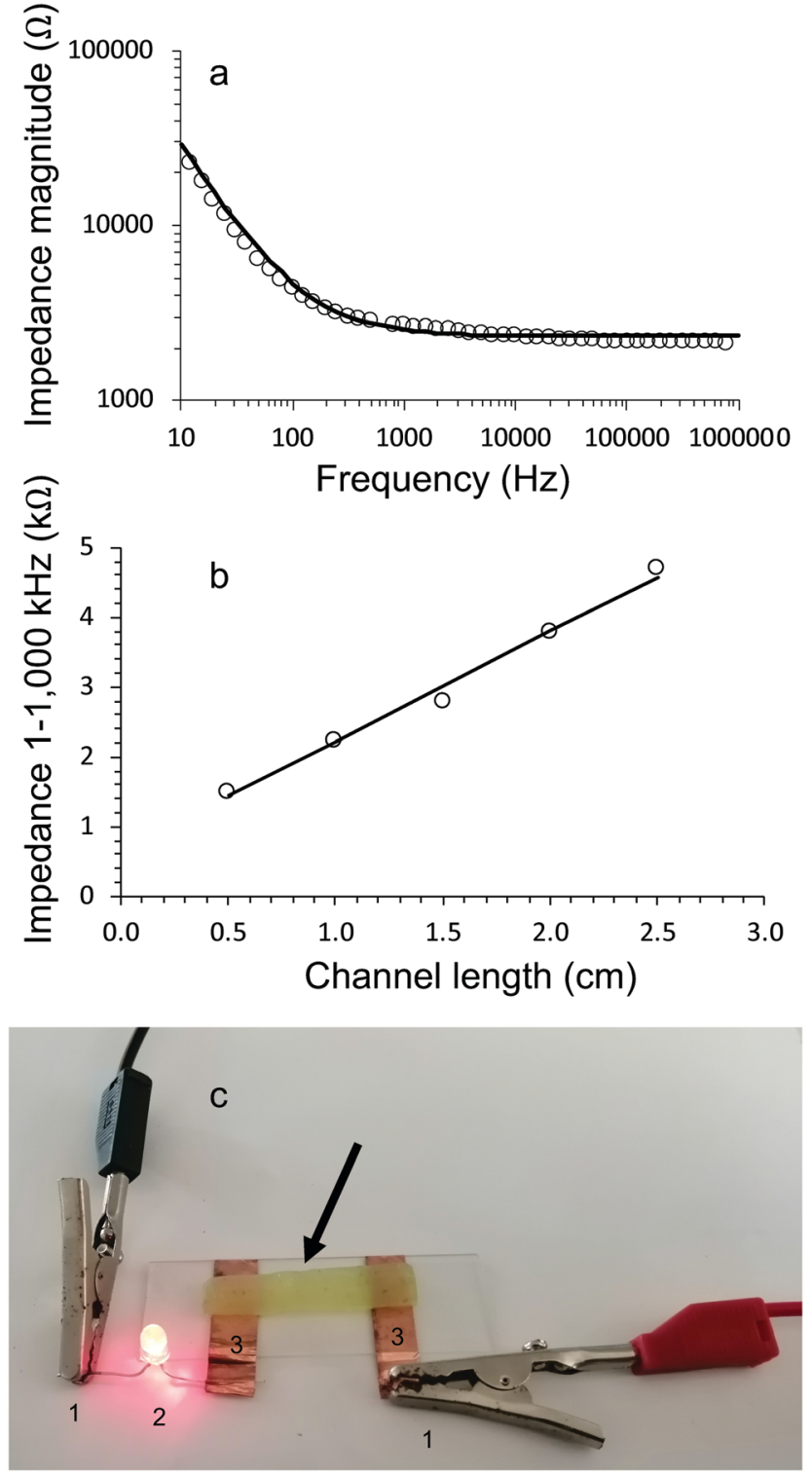

Fig. 7 Typical examples of electrical behaviour. (a) Impedance magnitude of algae/alginate gels crosslinked with $0.05 \mathrm{M} \mathrm{CaCl}_{2}$ (E1, spheres) as a function of frequency after 1 day of cultivation. Solid line is a fit to the data using an equivalent circuit as described in the main text. (b) Impedance in the frequency independent region $(1-1000 \mathrm{kHz})$ as a function of channel length for algae/alginate gels crosslinked with $0.05 \mathrm{M} \mathrm{CaCl}_{2}$ after 1 day of cultivation. (c) Photograph of an electronic circuit using a living electrode (algae/alginate gels crosslinked with $0.05 \mathrm{M} \mathrm{CaCl}_{2}$ after 14 days of cultivation) to complete the circuit and power the LED. Numbers 1-3 indicate alligator clips, red LED and copper electrodes, respectively. Arrow points to the living electrode.

$0.10 \mathrm{M} \mathrm{CaCl}_{2}$ ) on day 1 is $12.8 \pm 0.2 \mathrm{kPa}$, which is lower than the value $(16.1 \pm 0.4 \mathrm{kPa})$ for the corresponding gel prepared with algae. A drastic reduction of these storage modulus can be seen clearly between day 1 and 5 while after this point, storage modulus is staidly decrease till the end of algal growth period (Fig. 6a).

This is thought to once again be most likely a result of the algae consuming the crosslinking ions within the gel.
Furthermore, the algae were previously shown to increase the swelling ratio of the materials, therefore, the increase in water within these gels lowers the storage modulus of the samples. We have attempted to visual this phenomenon of the algae reducing the storage modulus (and increasing swelling ratio) in Fig. 6b.

\section{Electrical and impedance analysis}

Electrical characterisation of living electrode gel samples was carried out by running impedance sweeps from low to high frequencies. The Bode plot (Fig. 7a) for a typical gel shows that the impedance magnitude is inversely proportional to frequency until it plateaus and becomes independent of frequency above $1000 \mathrm{~Hz}$.

The impedance behaviour of all gels (with and without algae) could be modelled using equivalent circuits consisting of three components, i.e., a resistor and Warburg diffusion element in series and a capacitor in parallel. Fig. 7a show excellent correlation between the experimental data and equivalent circuit modelling.

The conductivity of the gels was obtained by plotting the resistive component (equivalent to impedance magnitude in the frequency independent region $1-1000 \mathrm{kHz}$ ) of hydrogel channel length, (Fig. 7b). The resulting data is fitted to Eqn 3, which allows the conductivity to be evaluated from the slope and the cross-sectional area.

All gels (with and without algae incorporated) exhibited conductivity values of approximately $6 \mathrm{mS} \mathrm{cm}^{-1}$ (Table 3). The conductivity of alginate gels (without algae) slightly reduced over 28 days. For example, the values for alginate gels crosslinked with $0.05 \mathrm{M} \mathrm{CaCl}_{2}$ reduced from $6.1 \pm 0.3 \mathrm{mS} \mathrm{cm}^{-1}$ on day 1 to $5.7 \pm 0.4 \mathrm{mS} \mathrm{cm}^{-1}$ on day 28 . The corresponding values for the algae/alginate gel $\mathrm{E} 1$ are: $6.2 \pm 0.5 \mathrm{mS} \mathrm{cm}{ }^{-1}$ on day 1 to $4.7 \pm 0.4 \mathrm{mS} \mathrm{cm}^{-1}$ on day 28 .

The conducting hydrogels were used in a simple circuit to connect LED to a power source (Fig. 7c). These measurements demonstrated that all hydrogels could function as electrode components. In particular, the algae containing gels are functioning as living electrodes.

\section{Conclusions}

In this study, alginate networks crosslinked with $0.05 \mathrm{M} \mathrm{CaCl}_{2}$ (E1), 0.1 $\mathrm{M} \mathrm{CaCl}_{2}$ (E2) and $0.1 \mathrm{M} \mathrm{CaCl}_{2}$ mixed with hydroxyapatite (E3) were used to immobilize the algae. The viability of algae within these gels was determined from dissolved oxygen ratio, microscopy and biomass measurements. Our findings showed that the viability of algal cells was maintained and increased over the cultivation period for all three alginate networks.

Mechanical analysis using compression testing and rheology revealed that the gels became softer over the algae cultivation period of 28 days. In particular, we demonstrated that incorporating algae results in a reduction in mechanical robustness, most likely due to the algae consumption of 
Table 3 Summary of electrical conductivity values for alginate gels $\mathrm{A} 1$ (crosslinked $0.05 \mathrm{M} \mathrm{CaCl}_{2}$ ), $\mathrm{A} 2$ ( $\mathrm{crosslinked} 0.10 \mathrm{M} \mathrm{CaCl}_{2}$ ) and $\mathrm{A} 3(2 \%$ hydroxyapatite and crosslinked $0.10 \mathrm{M} \mathrm{CaCl}_{2}$ ), and algae-alginate gels $\mathrm{E} 1$ (crosslinked $\left.0.05 \mathrm{M} \mathrm{CaCl}_{2}\right), \mathrm{E} 2$ ( $\mathrm{crosslinked} 0.10 \mathrm{M} \mathrm{CaCl}_{2}$ ) and E3 (2\% hydroxyapatite and crosslinked $0.10 \mathrm{M} \mathrm{CaCl}_{2}$ ) at $21^{\circ} \mathrm{C}$. Time indicates cultivation time

Conductivity $\left(\mathrm{mS} \mathrm{cm}^{-1}\right)$

\begin{tabular}{|c|c|c|c|c|c|c|}
\hline Time (days) & Gel A1 (no algae) & Gel E1 & Gel A2 (no algae) & Gel E2 & Gel A3 (no algae) & Gel E3 \\
\hline 7 & - & $5.8 \pm 0.3$ & - & $6.0 \pm 0.7$ & - & $6.2 \pm 0.5$ \\
\hline 14 & $5.8 \pm 0.5$ & $5.4 \pm 0.4$ & $5.9 \pm 0.5$ & $5.6 \pm 0.5$ & $6.0 \pm 0.3$ & $5.7 \pm 0.5$ \\
\hline 28 & $5.7 \pm 0.4$ & $4.8 \pm 0.4$ & $5.7 \pm 0.5$ & $4.9 \pm 0.4$ & $5.9 \pm 0.5$ & $4.9 \pm 0.2$ \\
\hline
\end{tabular}

crosslinkers. All gels exhibited the same swelling behaviour, i.e. an increase up to 14 days, followed by a decrease after 21 and 28 days.

Electrical impedance analysis was used to investigate the behaviour of the living electrode system. Equivalent circuit modelling showed that our living electrodes can be modelled as a resistor in series with a Warburg diffusion element and a capacitor. The living algae/alginate hydrogels exhibited conductivity values of $4.9 \pm 0.2 \mathrm{mS} \mathrm{cm}^{-1}$ (after 28 days) which allowed these materials to function as living electrode components in simple electrical circuits.

It is envisaged that living electrodes offer new possibilities for addressing the biological-electrical interfaces beyond the use of traditional materials such as gold and platinum.

\section{Conflicts of interest}

There are no conflicts to declare.

\section{Acknowledgements}

We thank the University of Wollongong (UOW) and the Australian Research Council Centre of Excellence for Electromaterials Science (CE140100012) for financial support. Dr Andrew Nattestad (UOW) is thanked for assistance with impedance measurements. M. A.-M. is supported by the Higher Committee for Education and Development Scholarship Program of Iraq.

\section{Notes and references}

1 A. K. Sarma, P. Vatsyayan, P. Goswami and S. D. Minteer, Recent advances in material science for developing enzyme electrodes, Biosens. Bioelectron., 2009, 24, 2313-2322.

2 H. C. P. Matthijs, H. Balke, U. M. Van Hes, B. M. A. Kroon and L. R. Mur, Application of Light-Emitting Diodes in Bioreactors: Flashing Light Effects and Energy Economy in Algal Culture (Ch/ore//a pyrenoidosa), Eur. Sp. Res. Technol. Cent., 1996, 50, 98-107.

3 X. A. Walter, J. Greenman, B. Taylor and I. A. Ieropoulos, Microbial fuel cells continuously fuelled by untreated fresh algal biomass, Algal Res., 2015, 11, 103-107.

4 A. L. Donne, et al., Solar Photovoltaics: A Review. Rev. Adv. Sci. Eng., 2013, 2, 170-178.
5 M. Ali, V. V. Starkov, E. A. Gosteva, A. V. Druzhinin and S. Sattar, Water Splitting Using Porous Silicon Photoelectrodes for Hydrogen Production, J. Phys.: Conf. Ser., 2017, 917, 052008.

6 G. A. Rechnitz, R. K. Kobos, S. J. Riechel and C. R. Gebauer, A bio-selective membrane electrode prepared with living bacterial cells, Anal. Chim. Acta, 1977, 94, 357-365.

7 F. Krujatz, et al., Green bioprinting: Viability and growth analysis of microalgae immobilized in 3D-plotted hydrogels versus suspension cultures, Eng. Life Sci., 2015, 15, 678-688.

8 R. A. Green, S. Baek, L. A. Poole-Warren and P. J. Martens, Conducting polymer-hydrogels for medical electrode applications, Sci. Technol. Adv. Mater., 2010, 11, 1-13.

9 S. Gupta and S. C. Agrawal, Survival of blue-green and green algae under stress conditions, Folia Microbiol., 2006, 51, 121-128.

10 D. J. Dickson and R. L. Ely, Silica sol-gel encapsulation of cyanobacteria: Lessons for academic and applied research, Appl. Microbiol. Biotechnol., 2013, 97, 1809-1819.

11 M. Martin, D. Portetelle, G. Michel and M. Vandenbol, Microorganisms living on macroalgae: Diversity, interactions, and biotechnological applications, Appl. Microbiol. Biotechnol., 2014, 98, 2917-2935.

12 H. Ochiai, H. Shibata, Y. Sawa and T. Katoh, 'Living electrode' as a long-lived photoconverter for biophotolysis of water, Proc. Natl. Acad. Sci. U. S. A., 1980, 77, 2442-2444.

13 U. Soltmann and H. Böttcher, Utilization of sol-gel ceramics for the immobilization of living microorganisms, J. Sol-Gel Sci. Technol., 2013, 48, 66-72.

14 H. M. Jensen, et al., Engineering of a synthetic electron conduit in living cells, Proc. Natl. Acad. Sci. U. S. A., 2010, 107, 19213-19218.

15 J. Yan, V. A. Pedrosa, A. L. Simonian and A. Revzin, Immobilizing enzymes onto electrode arrays by hydrogel photolithography to fabricate multi-analyte electrochemical biosensors, ACS Appl. Mater. Interfaces, 2010, 2, 748-755.

16 G. Wang, Z. Lei and Z. Jiujun, A review of electrode materials for electrochemical supercapacitors, ChemSusChem, 2012, 5, 797.

17 R. A. Green, et al., Living electrodes: tissue engineering the neural interface, IEEE Eng. Med. Biol. Soc. Annu. Conf., 2013, 2013, 6957-6960.

18 P. Fattahi, G. Yang, G. Kim and M. R. Abidian, A Review of Organic and Inorganic Biomaterials for Neural Interfaces, Adv. Mater., 2014, 26, 1846-1885. 
19 G. March, T. D. Nguyen and B. Piro, Modified electrodes used for electrochemical detection of metal ions in environmental analysis, Biosensors, 2015, 5, 241-275.

20 J. N. Rosenberg, G. A. Oyler, L. Wilkinson and M. J. Betenbaugh, A green light for engineered algae: redirecting metabolism to fuel a biotechnology revolution, Curr. Opin. Biotechnol., 2008, 19, 430-436.

21 R. Ramanan, B. H. Kim, D. H. Cho, H. M. Oh and H. S. Kim, Algae-bacteria interactions: Evolution, ecology and emerging applications, Biotechnol. Adv., 2016, 34, 14-29.

22 M. D. Brasier, O. R. Green, A. P. Jephcoat, A. K. Kleppe, M. J. Van Kranendonk and J. F. Lindsay, Questioning the evidence for Earth's oldest fossils, Nature, 2002, 416, 76-81.

$23 \mathrm{~K}$. Abe and N. Nishmura, Simultaneous production of $\beta$-carotene, vitamin $\mathrm{E}$ and vitamin $\mathrm{C}$ by the aerial microalga Trentepohia aurea, J. Appl. Phycol., 1999, 11, 33-36.

24 X. Yang, F. Guo, S. Xue and X. Wang, Carbon distribution of algae-based alternative aviation fuel obtained by different pathways, Renewable Sustainable Energy Rev., 2016, 54, 1129-1147.

25 C. Safi, B. Zebib, O. Merah, P.-Y. Pontalier and C. VacaGarcia, Morphology, composition, production, processing and applications of Chlorella vulgaris: A review, Renewable Sustainable Energy Rev., 2014, 35, 265-278.

26 R. Lei, W. Qiao, F. Hu, H. Jiang and S. Zhu, A simple and effective method to encapsulate tobacco mesophyll protoplasts to maintain cell viability, MethodsX, 2015, 2, 24-32.

27 Y. Li, et al., Characterization of a microalga Chlorella sp. well adapted to highly concentrated municipal wastewater for nutrient removal and biodiesel production, Bioresour. Technol., 2011, 102, 5138-5144.

$28 \mathrm{Z}$. Wu and X. Shi, Optimization for high-density cultivation of heterotrophic Chlorella based on a hybrid neural network model, Lett. Appl. Microbiol., 2007, 44, 13-18.

29 J. Harrington and E. Morris, Conformational ordering and gelation of gelatin in mixtures with soluble polysaccharides, Food Hydrocolloids, 2009, 23, 327-336.
30 J. A. Rowley, G. Madlambayan and D. J. Mooney, Alginate hydrogels as synthetic extracellular matrix materials, Biomaterials, 1999, 20, 45-53.

31 J. L. Drury and D. J. Mooney, Hydrogels for tissue engineering: Scaffold design variables and applications, Biomaterials, 2003, 24, 4337-4351.

32 Y. Ferro, M. Perullini, M. Jobbagy, S. A. Bilmes and C. Durrieu, Development of a biosensor for environmental monitoring based on microalgae immobilized in silica hydrogels, Sensors, 2012, 12, 16879-16891.

33 C. Chouteau, S. Dzyadevych, J. M. Chovelon and C. Durrieu, Development of novel conductometric biosensors based on immobilised whole cell Chlorella vulgaris microalgae, Biosens. Bioelectron., 2004, 19, 1089-1096.

34 Y. Sun, Y. Song and J. Paik, Characterization of silicone rubber based soft pneumatic actuators, IEEE/RSJ Int. Conf. Intell. Robot. Syst., 2013, 4446-4453.

35 M. Di Giuseppe, et al., Mechanical behaviour of alginategelatin hydrogels for 3D bioprinting, J. Mech. Behav. Biomed. Mater., 2018, 79, 150-157.

36 L. Fan, et al., Preparation and Characterization of Alginate/ Poly(Vinyl Alcohol) Blend Fibers, J. Macromol. Sci., Part A: Pure Appl. Chem., 2005, 42, 41-50.

37 B. Sarker, et al., Fabrication of alginate-gelatin crosslinked hydrogel microcapsules and evaluation of the microstructure and physico-chemical properties, J. Mater. Chem. B, 2014, 2, 1470.

38 K. L. Lee and D. J. Mooney, Alginate: properties and biomedical applications, Prog. Polym. Sci., 2013, 37, 106-126.

39 E. Ruvinov and S. Cohen, Alginate biomaterial for the treatment of myocardial infarction: Progress, translational strategies, and clinical outlook. From ocean algae to patient bedside, Adv. Drug Delivery Rev., 2016, 96, 54-76.

40 J. Kaparapu, M. Narasimha and R. Geddada, Applications of immobilized algae, J. Algal Biomass Utln., 2016, 7, 122-128. 